Original Research Article

\title{
The Asymmetric Impact of Weighting Economic and Political Events on the Fluctuations of Banking Group Index (Case of Tehran Stock Exchange)
}

\author{
Saeed Dehghan Khavari" \\ Maryam Iraji ${ }^{*}$ \\ Seyed Hossein Mirjalili ${ }^{\dagger}$
}

Received: 06 Jun 2021

Approved: 15 Jan 2022

Stock Exchange Investors have paid more attention to the banking group in recent years so that in many cases, the direction of the banking index has changed the general direction of the market. Therefore, exploring the banking index fluctuation is important from the point of view of investors as well as the direction of the market. The purpose is to examine the effectiveness and direction of news, as one of the most important factors in the formation of volatility, on the banking group index in Tehran Stock Exchange by using 1460 daily records during 2018-2019 and the GARCH family's method. The data were collected for four different newsgroups, including economic, political, psychological, and financial. After that, the news that had more relationship with the banking group was separated to underscore in the weighting stage and divided into the positive and negative news, according to the perspectives of capital market experts and economic elites. The results indicated that newsgroups have a significant effect on the group index, and only the negative political model on the banking group has an asymmetric effect. The results indicated that political and economic news has a positive and significant impact on banking index fluctuations.

Keywords: Capital Market, Banking Group Index, Economic and Political Event, Asymmetric Effect, Exponential GARCH.

JEL Classification: C58, G15, G41

\footnotetext{
* Department of Economics, Meybod University, Meybod, Iran; saeed.khavari@ meybod.ac.ir (Corresponding Author)

$\dagger$ Faculty of Economics, Institute for Humanities and Cultural Studies, Tehran, Iran;

h.jalili@ihcs.ac.ir

* Department of Financial Engineering, Science and Arts University, Yazd, Iran;

maryamirajii@gmail.com
} 


\section{Introduction}

Understanding the behavior of the stock market and the effect of political or economic events on the fluctuations of the capital market is crucial, given the role and significance of the capital market in economic growth and development (Long et al., 2018).

For analyzing stock price fluctuations, an index that deserves more attention is the banking group index. Increasing the share of banks in the capital market and the entry of private banks into this market enhanced their role in orienting the market and their greater influence in orienting the entire market and the influence of other groups. On the other hand, increasing the share of banks in the capital market provoked more investors to turn to it.

Therefore, identifying and analyzing the factors affecting its changes and fluctuations is important. An asset price such as a banking sock is affected by its risk or its conditional fluctuations. It primarily depends on the performance of the firm and economic and political events as well. Events are external factors affecting the capital market.

With the Internet development, news affecting stock prices and its forecasts spread fast using automated, intelligent computer systems. The development of cyberspace and financial and news blogs have also made the capital market more dynamic. So that researchers find that the return on investment is advertised on Facebook, Google, Twitter, and Yahoo and reflects the significant impact of news on the capital market (Chen \& Chen, 2017).

In some cases, the effect of environmental factors on the success or failure of a company or organization and consequently the stock price is far more effective than management factors (Atsalakis \&Valavanis, 2009).

Political factors impact the fluctuations in the shareholders' tendency to buy and sell stocks. For example, with the positive trend of events, the stock index changes. However, according to the results of the path analysis technique, psychological factors of the market have the most direct and indirect effect on the shareholders' financial decisions after political factors (Briz \& Lott, 2011).

Therefore, we examine whether there is a significant relationship between economic, political, financial events and the banking group index and whether its effect is asymmetric. The paper is organized as follows: The second section describes the theoretical background. The third section presents the literature review, and the fourth section is devoted to methodology. The fifth section 
provides estimation results, and finally, the sixth section presents our conclusions.

\section{Theoretical Background}

Instead of checking stock prices individually, we can use an indicator, which shows the general price or return among companies. Stock market price indices are used to determine the general prices or returns among all or a group of listed companies on the stock exchange. The total Stock price index represents the general level of prices of the listed companies on the stock exchange. Likewise, the return index (value and cash return) also reflects the general level of return of the companies listed on the securities market.

Factors affecting the stock prices are classified into internal and external factors. The company's operations and decisions constitute internal factors impacting stock prices. External factors include factors beyond the authority of the company's management and affect the way a company operates. Thus, the impact of external factors such as political issues on managerial performance needs to be considered as important (Atsalakis \&Valavanis, 2009).

On the other hand, two factors are the basis for investment which are risk and return. The systematic risk (market risk) arises from environmental conditions and is not controlled by the companies. It seems that this risk in developing economies is high due to extensive and severe changes of environmental factors, and therefore, the effect of macro-economic variables (environmental factors) on the stock price index has been investigated repeatedly. (Gholami, 2019)

In this regard, events can affect both risk and return positively or negatively. By increasing Internet access, news on the stock market release fast, and as a result, price forecasts made possible using automated, intelligent computer systems (Chen \& Chen, 2017).

Moreover, given the volume of messages that are exchanged through stock exchange online databases, it is not unreasonable to say that these messages reflect decisions. For example, between 1998 and 2001, more than 12 million messages related to US companies were transmitted via Yahoo Finance. (Antweiler \& Murray, 2002).

Regarding the capital market, two categories of events are given more attention: economic (including financial) and political incidents. Good and bad economic, financial, and political events can play an important role in stock prices, especially in developing countries. Good and bad news on Exchange rate changes, earnings reports, unfortunate occurrences, 
uncertainty, liquidity growth, and unexpected news can be considered as factors impacting the Stock Exchange's total index.

It is noteworthy that in oil-dependent developing countries, incidents related to oil prices and exchange rates are important because, in oil-dependent economies, the profitability of many companies is directly or indirectly affected by oil price changes. The rise in oil prices gives rise to optimistic expectations about the growth of some economic activities (such as the oilproducing activities as well as the non-tradable sector such as services and housing). In contrast, tradable goods suffer from rising oil prices of imported goods.

Exchange rate changes can affect the stock price index in two ways. First, a trade company revenue is directly related to the exchange rate. Second, foreign exchange as a competing asset in the portfolio of economic entities influences their decisions on buying and selling stocks. As in the developing countries, many activities rely on imports from industrialized countries. Therefore, exchange rate fluctuations affect companies' profits, and exchange rate fluctuations may change the competitive position of domestic producers (Bollen et al., 2011).

As an example of a political event, nuclear negotiation is a political issue in recent years that has been influential on investor decision-making. Investors in the stock market are generally overly responsive to the information and news of nuclear negotiations in the market. In the financial markets, this information made reactions and resulted in stock price changes.

In addition to the real effects of news on stock prices mentioned in the previous paragraphs, its psychological and sociological aspects in developing countries should not be overlooked.

Events affect indicators that overshadow the psychological aspect of the market. Words have a strong influence. Their message exerts energies that lead the audience to react to the message. The content of the economic or financial message we convey has an impact on the economic world. At any moment, we create something positive or negative with the words we use.

Moreover, observations show that the content of financial news of the stock market can be related to psychological and sociological aspects of shareholders (Zhang et al., 2017).

Fama (1990) indicated that a company's economic activities could justify only $50 \%$ of stock price changes. The researchers were surprised that they couldn't explain most of the changes in stock prices. Economists and psychologists have underlined the possible role of emotions in economic 
decision-making. It is assumed that news plays an important role in explaining price changes in financial markets.

Behavioral bias by capital market investors makes the gap between market prices and their intrinsic value. In the over-reactive process, the market initially reacts to new information, but over time, the market finds out its mistake and prices balance (Riahin et al., 2016).

Therefore, financial markets do not always conform to the efficient market hypothesis, and especially qualitative information is not fully and immediately reflected in stock prices. In this regard, many event studies examined stock prices before and after the day, so-called "event day." Market reaction to an incident even before the event day is usually called "information leakage." Another issue about behavioral finance is that good and bad news may be provocative that affect human behavior (Seok et al., 2019).

In the financial market, this information can be reflected in different signals, news, and forecasts from inside or outside the company, making it available to shareholders, and provocate reactions resulting in stock price changes. Stocks market reactions to the news are different, and in some cases, they are not rational, causing fluctuations in stock prices. Herding behavior happens when people set prices higher or lower than actual prices, according to new information. Although markets realize the mistake and return to equilibrium over time, this behavior is considered a kind of irrational behavior in the market, which can be a reasonable answer to the perceived uncertainty of investors. It is usually accompanied by a price return (Ghalibaf Asl, 2006).

Also, the market response to positive and negative shocks is different. Investors' concerns about negative information are more affected, and this news has a greater impact on the individual's mood (Lalwani et al., 2019).

Black (1976), Christie (1982), and Nelson (1991) indicated that negative shocks (bad news) have a greater impact on returns fluctuations compared to the positive shocks of the same size so that the fluctuations in the stock markets are asymmetric (Mehrara \& Abdoli, 2006).

\section{Literature Review}

Gholami (2019) examined the relationship between news on gold and fluctuations in the Tehran Stock Exchange. The results indicated that with 95\% confidence in six months, the news related to gold is not effective in the Tehran Stock Exchange index fluctuations. It means that there is no statistically significant relationship between news on gold and fluctuations in the Stock Exchange. 
Narayan (2019) examined whether crude oil price news contributes to predicting stock returns, using data on negative and positive news of oil prices from 100 sources around the world, including 59,129 news articles on oil prices. The models were estimated for 45 countries. The results indicated that (a) negative and positive news can predict stock returns for a maximum of 12 countries, while oil prices did not predict returns. (B) Three oil price indices together have only been able to predict the returns of 23 countries. Thus, news on oil prices seems to have more helpful in predicting returns.

Zhao (2019) explored inferring private information from news and online searches using correlation and forecast in the Chinese stock market. The results show that online news and searches have a positive relationship with stock performance indices, while private information negatively correlates with turnover and fluctuations. News and online searches are also good predictors of the capital market index, and private information helps forecast index fluctuations.

Li (2018) examined how the Chinese stock market reacted to different news on Xiong'an's New Zone Strategy. In this regard, news related to Xiong collected and categorized them into emotions and source of views. The results suggest that negative news deters people from trading stocks. The results also show that news from state media has a greater impact on the stock market than news from other sources. Also, scientific and academic news is more effective than other ones.

$\mathrm{Wu}$ et al. (2017) explored whether economic news can predict Taiwan Stock Market returns. They developed a fixed-effect model to examine stock returns in 20 sub-categories from 2008 to 2014. The results suggest that news variables provide effective information for predicting stock returns in Taiwan. The results also show the asymmetric effect of economic news on the forecast of stock returns. Moreover, the accuracy of prediction is higher during the stock market boom than over a recession period.

Zhang et al. (2017) examined the simultaneous as well as lagged relationship between financial news in the mass media and news in the new media in the Chinese Stock Market. The results show a very strong correlation between the news of two media. Also, new media are increasingly playing a key role in the Chinese Stock market.

Riahin et al. (2016) assessed the overreaction of Iranian stock market investors to nuclear negotiation news using the event effect model. The 12year research period of 2003 is the beginning of the negotiations from 2003 to January 2016. The $\mathrm{Z}$ statistical test confirmed the results. The results indicated 
that investors in the Tehran stock exchange overreacted to the information and news of nuclear negotiations.

Mashayekh et al. (2013) explored the impact of news on the capital market. Given that technological advancement has facilitated disseminating news, part of the news is dedicated to the capital market and its variables and related events. Therefore, the effect of the news on the capital market has been discussed based on the theories on the reaction to the news.

Moazeni and Asadollahi (2013) examined the impact of political and economic news on gold coin price fluctuations in Iran using ARCH and EGHARCH models. They find that gold coin price changes were not constant over time. Also, the effect of good and bad political and economic news on the gold coin price fluctuations is asymmetric, as good political news has the most effect on the gold coin price fluctuations, and there is no significant relationship between gold coin price changes and economic news. The result indicated that the gold coin market is rather affected by psychological issues. It was expected that good (bad) political news decreases (increase) gold coin price, but the result was contrary to what was expected.

Heibati and Zandieh (2011) investigated the emotional behavior of investors in Tehran Stock Exchange due to the global financial crisis news. They addressed investors' reactions in the non-immediate matching of securities prices based on two hypotheses of over-reaction and inconsistent information. The findings indicated the compatibility of shareholders' returns with the above two hypotheses and increased market uncertainty in some stocks, and the shareholders' overreaction in some stock exchange industries when the news was released on the global financial crisis.

Yahyazadeh far et al. (2010) stated that various factors cause the financial behavior of investors and their decision-making in the Tehran Stock Exchange. They classified these factors into four categories: political, economic, domestic, and psychological. The results indicated that political factors $(62 \%)$, psychological factors (53\%), economic factors $(47 \%)$, and internal factors (31\%) impacted on buying and selling of stocks.

\section{Methodology}

At First, data collected for four different newsgroups, including economic, political, psychological, and financial. Economic news is defined as news on economic variables such as economic growth, industrial production, prices of industrial products, non-oil exports, exchange rates, unemployment and employment rates, budget deficit and trade balance deficit, taxes, monetary policy, etc. 
Political events are divided into three areas: the opinion of political officials, domestic political developments, and foreign political developments.

Psychological factors also include news releases, market rumors, and consulting on investment and financial factors, including balance sheet data, financial ratios, risk \& return, and turnovers.

Then, for each index of the banking group and the index of other groups, the news that had more to do with their activities were separated to underscore in the weighting stage. Then, economic, financial, and behavioral economic news (economics-related psychological news) were selected to impact banking, chemical, and basic metal groups. Also, political and behavioral political news (politics-related psychological news) were included in the political news collection.

In the next stage, economic and political news is divided into two parts, positive and negative news, according to the perspectives of capital market experts and economic elites. Of course, the opinion of experts is based on the fact that the criterion for being positive and negative is the increase in the banking and other groups.

Finally, news categories are classified as follows: positive economic news, negative economic news, positive political news, negative political news. Altogether it includes a total of 1460 data. It consisted of data from March 21, 2018, to March 20, 2019. Information on the Stock Exchange Index for the three groups of banking, chemicals and basic metals is collected from the official stock exchange website.

The news was collected from two Boursenews and Farsnews sites. Finally, the data were weighted through the Delphi method by the industry experts. Moreover, the news was rated by stock exchange experts according to the importance of the news from 0 to 10 .

The estimation method is the asymmetric GARCH method to examine the significance of events on the fluctuations of the banking group index. Using the exponential GARCH (EGARCH) method allows measuring the asymmetric effects of good and bad events because GARCH models can better analyze and evaluate the effect of a variable on another variable that has behavioral fluctuations; such as exchange rates and capital market indices. The exponential GARCH method also has the property to investigate the asymmetry of a variable on the fluctuations of the selected group of stock prices. 
In fact, a practical model to measure exogenous shocks is the EGARCH method, which Nelson (1991) first used to measure asymmetric effects that are shown in the following equation:

$\ln \sigma_{t}^{2}=\alpha_{0}+\alpha_{1} \frac{\left|u_{t-1}\right|}{\sqrt{\sigma_{t-1}^{2}}}+\beta \ln \sigma_{t}^{2}+\gamma \frac{u_{t-1}}{\sqrt{\sigma_{t-1}^{2}}}$

Where $u_{t}$ denotes residual terms and $\sigma_{t}^{2}$ is known as the conditional variance. A problem for the $\mathrm{ARCH}$ model is that good/bad news is considered to be of the same size, so they have the same symmetric effect, but the market may respond differently to bad news with equal magnitude. Therefore, the asymmetry test and its incorporation into the $\mathrm{ARCH}$ model are very important. Given that there are ARCH in the stock changes, therefore, as the index changes over time are not the same, and the impact of news and events on index changes is expected to be asymmetric, exponential GARCH was chosen for estimating the model (Souri, 2020).

However, in the symmetric GARCH model, the variabilities (variances) are the same for positive and negative shocks. GARCH models have been developed to accommodate the effects of positive and negative shocks asymmetrically. We examined three types of models, GJR, TGARCH, and exponential GARCH or EGARCH models. General GARCH models are currently widely used to estimate volatility in financial markets. The simple GARCH model shows that volatility is not a constant value over time. Over time, after introducing GARCH models, for some other heterogeneous properties of variances such as the effect of asymmetric shocks and finite instability, EGARCH models were introduced by Nelson (1991). (Keshavarz Haddad \& Heidari, 2010)

\section{Estimation Results}

We applied the stationary test to index variables. It should be noted that for the asymmetry purpose, we compared the banking group index with both chemical and basic metal indices. However, the data for all three groups requires a stationary test. The results of Augmented Dickey-Fuller and Phillips-Perron unit root tests are provided in Table (1). Bank denotes bank index, Chemi denotes chemical index, Metal denotes metal index, Polpos denotes positive political news, Polneg denotes negative political news, Ecopos denotes positive economic news, and Econeg denotes negative economic news. 
Table 1

Stationary test for banking, chemical and basic metal group index

\begin{tabular}{lll}
\hline Stock Exchange index & ADF Test & PP Test \\
\hline Banking Index & $3.07^{*}$ & $2.87^{*}$ \\
Chemical Index & $2.15^{*}$ & $2.08^{*}$ \\
Basic Metals Index & $3^{*}$ & $2.04^{*}$ \\
\hline
\end{tabular}

*shows significance at 5\%

Source: Research Findings

Table (1) shows the result of stationary test of degree 0.5 for three group indices. When the result in the statistic column is within the absolute magnitude range of the number resulted in the t-Statistic column, the variable is stationary. In the above test, all three indices are stationary because the statistics results are not within the range of t-Statistic. For example, in the Banking Group Index, the resulted statistic number is 3.07, which is not in the range of 1.94, so the target index is stationary. The index growth chart also shows the stationary of the data. The index chart of the banking group is presented in Figure (1) with severe fluctuations.

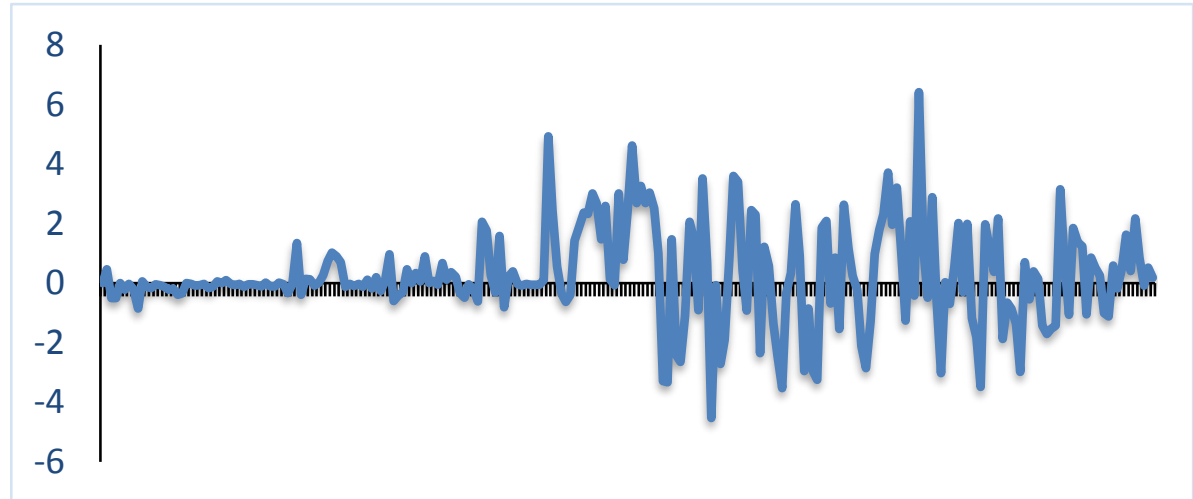

Figure 1. Banking Group Index Growth (from March 21, 2018, to March 20, 2019) Source: Research Findings

Compared to the banking index, the situation of the two basic metals and chemical indices can be seen. According to figure (2), are observed severe fluctuations in these two indicators. 


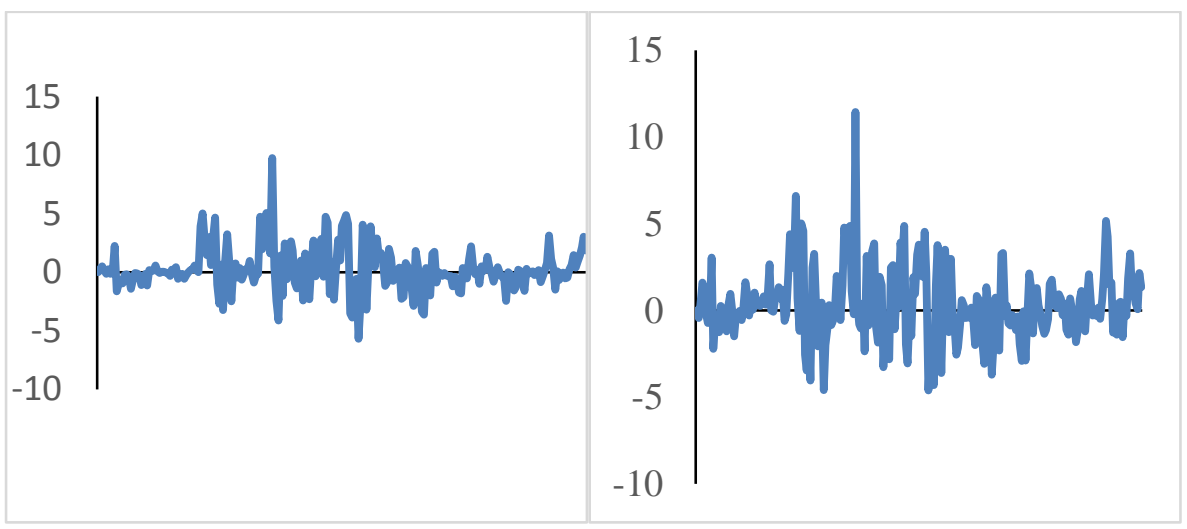

Figure 2. Chemical (left) and Basic Metals (right) Group Indices Growth Chart Source: Research Findings

As the time series used in this study are daily and have high frequency, we expect that there will be ARCH effects that the test can ascertain. After examining the stationary test, we need to examine the data with another test to determine ARCH behavior. Therefore, we need to examine the GARCH behavior for the banking group index, and for this purpose, we use the ARCH's variance heterogeneity test and run simple regression.

To this end, we regress the banking group index with a lag and then examine ARCH behavior in the index by using the variance homogeneity test.

Table 2

Arch test for banking, chemical, and basic metal group indices

\begin{tabular}{lll}
\hline Indices & Test Statistics & Probability \\
\hline Banking index & 14.06 & 0.00 \\
Chemical Index & 12.37 & 0.00 \\
Basic Metals Index & 286.2 & 0.00 \\
\hline
\end{tabular}

Source: Research Findings

To check the ARCH behavior in this test, the variable has an ARCH behavior if the probability is less than 0.05. By examining Table (2), changes in the banking group index have arch behavior as well as other indices; we use ARCH family models to investigate the factors affecting the index fluctuations and changes.

Then, we examine the impact of positive economic, adverse economic, positive political, and negative political news on the banking index. To select 
the best estimation method, asymmetric GARCH models such as GJR, TARCH, and EGARCH were used to determine the best one. Table (3) describes the models to estimate the variables.

Table 3

Estimation models for Banking Index

\begin{tabular}{lll}
\hline Events & & Model \\
\hline Economic News & Positive & EGARCH $(1,1)$ \\
\cline { 2 - 3 } & Negative & GJR $(1,1)$ \\
\hline Political News & Positive & EGARCH $(1,1)$ \\
\cline { 2 - 3 } & Negative & TGARCH $(1,1)$ \\
\hline
\end{tabular}

Source: Research Findings

The results of the estimation are presented in table (4)

Table 4

Results of Economic News Models for Banking Index

\begin{tabular}{lll}
\hline Variable & Coefficient & Probability \\
\hline Ecopos & 0.143 & 0.000 \\
Asymmetric effect & 0.15 & 0.971 \\
Econeg & -11.39 & 0.000 \\
Asymmetric effect & 0.14 & 0.312 \\
\hline
\end{tabular}

Source: Research Findings

The effect of positive economic news in the banking index is significant and has a positive effect. The effect of negative economic news on the banking groups was significant and had a negative effect. The results of positive economic news models are as expected.

Table 5

Results of Political News Models for Banking Index

\begin{tabular}{lll}
\hline Variable & Coefficient & Probability \\
\hline Polpos & -0.118 & 0.002 \\
Asymmetric effect & -0.135 & 0.252 \\
Polneg & -13.6 & 0.000 \\
Asymmetric effect & 0.143 & 0.000 \\
\hline
\end{tabular}

Source: Research Findings

The effect of positive political news was significant but had a very weak negative effect on the banking group index. However, the negative effect of 
political news was significant and negatively impacted the banking group. The results of positive political news are not as expected, and its impact on the fluctuations of the banking index is fragile. The result of the negative political news is as expected and has a negative and significant effect. Therefore, negative political and economic news had the greatest impact on the banking index, respectively.

Also, in the models, we are looking for symmetric or asymmetric variables. For symmetry analysis, if the positive and negative shocks have the same impact, the variables have the symmetric effect. If the variables have different impacts, the variables have an asymmetric effect.

Put it differently; in EGARCH models, if parameter $\gamma$ in equation (1) is not significant, then it means that shocks on the banking group index are symmetric. Therefore, by the GARCH family models, we analyzed the asymmetric effect of the indices. By examining the effect of the news of four groups on the banking group index, only the negative political news is significant because the probability for the variable is less than 0.05 , and it has an asymmetric effect, and the symmetric effect is rejected. The other variables, which include positive political, and positive and negative economic news, have greater than 0.05 probability, and their asymmetric effect has been rejected, and the symmetric effect is confirmed.

Here we compare the results for the banking index with the effects of news on the basic metals and chemical indices as two important groups in the Tehran Stock Exchange. It is because of comparing the banking index result with these two groups, as important indices of the capital market, from effectiveness and direction of effects.

Thus, we examine the impact of positive economic and negative economic, positive political, and negative political news on basic metals and chemical indices.

Table 6

Estimation results for Chemicals and basic Metals indices

\begin{tabular}{lll}
\hline Variable & Chemicals Index & Basic Metals Index \\
\hline Positive Economic News & EGARCH $(1,1)$ & EGARCH $(1,1)$ \\
Negative Economic News & GJR & EGARCH $(1,1)$ \\
Positive Political News & EGARCH $(1,1)$ & GJR $(1,1)$ \\
Negative Political News & EGARCH $(1,1)$ & EGARCH $(1,1)$ \\
\hline
\end{tabular}

Source: Research Findings

The results of the model estimation are presented in Table (7) 
Table 7

Significance Probability of Groups indices

\begin{tabular}{|c|c|c|c|}
\hline Variable & $\begin{array}{l}\text { Chemicals } \\
\text { Index }\end{array}$ & $\begin{array}{l}\text { Basic } \\
\text { Index }\end{array}$ & Metals \\
\hline Ecopos & $\begin{array}{l}0.448 \\
(0.000)\end{array}$ & $\begin{array}{l}56.7 \\
(0.070) \\
\end{array}$ & \\
\hline Econeg & $\begin{array}{l}-52.4 \\
(0.041) \\
\end{array}$ & $\begin{array}{l}0.00 \\
(1.00) \\
\end{array}$ & \\
\hline Polpos & $\begin{array}{l}-0.039 \\
(0.028)\end{array}$ & $\begin{array}{l}-1.03 \\
(0.00)\end{array}$ & \\
\hline Polneg & $\begin{array}{l}-0.165 \\
(0.001) \\
\end{array}$ & $\begin{array}{l}-58.7 \\
(0.000) \\
\end{array}$ & \\
\hline
\end{tabular}

Source: Research Findings

The results can be summarized in this way. The effect of positive economic news in all three index groups is significant and has a positive effect, which has a higher effect on the basic metals index. The effect of negative economic news on the chemical and banking groups was significant, and the chemicals group had a high impact. Also, positive political news was significant in all three groups and had a high impact on the basic metals index, and negative political news was significant in all three groups and had a high impact on the banking group.

The results of Table (7) can be analyzed based on the selected indices groups. In the chemicals group, the negative economic news had the highest effect, and then the positive economic news had the greatest effect on the target index as a result of the economic news. In the banking group, negative political news and negative economic news outperformed the rest of the news. In the metals group, positive political news and negative political news had the highest impact.

Table 8

Asymmetric effect probability of selected groups

\begin{tabular}{lll}
\hline Variable & Chemicals Index & Basic Metals Index \\
\hline Positive Economic News & 0.000 & 0.000 \\
Negative Economic News & 0.001 & 0.967 \\
Positive Political News & 0.000 & 0.000 \\
Negative Political News & 0.010 & 0.000 \\
\hline
\end{tabular}

Source: Research Findings 
The symmetric effect of the chemical group index is rejected, and the asymmetric effect is confirmed, which means that all good and bad news impact the variable unequally.

As for the basic metals group, the negative economic news was not significant, so it has a symmetric effect on the intended index, and the rest news had an asymmetric effect.

In general, there was no symmetric behavior in the chemicals group, unlike the banking group in which the asymmetric behavior was indicated only on negative political news. Therefore, symmetric behavior is not dominant in chemicals and basic metals groups, and behaviors are asymmetric.

\section{Conclusion}

The results of this study indicate the significance of all four groups of positive and negative economic news as well as positive and negative political news on the banking group index, meaning that the news has an impact on the banking group index. A significant result for the banking index is that negative news and events have a significant effect. The negative political and economic news had an effect of -11 and -13.6 on the banking index. One of the reasons could be the emotional state of the Iranian market and investors. Negative news shocks, such as sanctions, which have been intermittently applied to Iran's economic environment in recent years, have also increased the effects of negative news. In this situation, the fear of a more severe negative event causes the market to overreact. Another point is that negative events limited to the banking sector, such as sanctions on banks and the central bank, which has intensified the reactions of the banking index, as expectations of negative news increase, it will exacerbate current market reactions.

From the viewpoint of symmetry or asymmetry of impact, only the negative political model has an asymmetric effect on the banking group index, meaning that positive and negative shocks on the indices are different, and others equally affect the banking group index. But results show that the symmetric behavior is not dominant at all in chemicals and basic groups, and behaviors are asymmetric.

Therefore, the research hypothesis that there is a significant relationship between economic, political, financial events and the banking group index is confirmed. But the hypothesis of asymmetry is rejected except for negative political news

A comparison between the banking index with the two basic metals and chemical indices indicated that the effect of positive economic news on the fluctuations of the three indices has been positive. However, the impact of the 
banking index is less compared to the other two indicators. Moreover, positive economic news has a significant and positive effect on all three index groups, which has a higher effect on the basic metals index.

This difference also exists in negative economic news. The banking index is less influential than the chemical index. So, Negative economic news in the chemical and banking groups was significant, and in the chemical group had an insignificant impact.

Regarding the effect of positive political news, the reaction of the banking index is similar to the other two indices. Unlike positive political news, negative political news has the expected effect on the banking group index and other indices, which is significant for the banking group. A similar situation is observed for the basic metals group index.

In general, negative news has a greater impact on the banking index as well as the other two indicators than positive news.

\section{References}

Antweiler, W. and Murray, Z. (2002). Internet Stock Message Boards and Stock Return. Working Paper. The University of British Columbia.

Atsalakis, G. S., \& Valavanis, K. P. (2009). Surveying Stock Market Forecasting Techniques - Part II: Soft Computing Methods. Expert Systems with Applications. 36(3), 5932-5941.

Black, F. (1976). Studies of Stock Price Volatility Changes. In Proceedings of the 1976 Meeting of the Business and Economic Statistics Section. American Statistical Association, Washington DC, 177-181.

Bollen, J., Mao, H., \& Zeng, X. (2011). Twitter Mood Predicts the Stock Market. Journal of Computational Science, 2(1), 1-8. https://doi.org/10.1016/j.jocs.2010.12.007

Birz, G. and Lott, J. (2011). The Effect of Macroeconomic News on Stock Returns: New Evidence from Newspaper Coverage. Journal of Banking \& Finance, 35(11):2791-2800

Chen, M., \& Chen, T. (2017). Modeling Public Mood and Emotion: Blog and News Sentiment and Socio-Economic Phenomena. Future Generation Computer Systems, 96, 692-699, https://doi.org/10.1016/j.future. 2017.10.028

Christie, A. (1982). The Stochastic Behavior of Common Stock Variances: Value, Leverage and Interest Rate Effects. Journal of Financial Economics. Volume 10(4) 407-432.

Ghalibaf Asl, H., \& Naderi, M. (2006). Investigating Over-Response of Tehran Stock Exchange Investors to Information and News Released in Prosperity and Recession. Journal of Financial Research, No. 21, 8th Year, 97-112.

Gholami, M. (2019). Investigating the Relationship between Gold and Housing News with Stock Exchange Fluctuations. First National Conference on Research and 
Development in Resistance Management and Economics, Tehran Management and Development Research Institute.

Fama, E. F. (1990). Stock Returns, Expected Returns, and Real Activity. The Journal of Finance, 45(4), 1089-1108.

Heibati, F., \& Zandieh, V. (2011). Stock Market Investors' Over-Response to Global Financial Crisis News. Journal of Financial Knowledge of Securities Analysis, No. 9 (4), 75-100.

Keshavarz Haddad, Gh., \& Heidari, H. (2010). The Impact of Political News on Tehran Stock Exchange (AFIGARCA and MSM) Approach. Journal of Economic Research, 46(1), 111-135.

Lalwani, V., Sharma, U., \& Chakraborty, M. (2019). Investor Reaction to Extreme Price Shocks in Stock Markets: A Cross Country Examination. IIMB Management Review, 31 (3), 258-267. https://doi.org/10.1016/j.iimb. 2019.03.004

Li, k. (2018). Reaction to News in the Chinese Stock Market: A Study on Xiong'an New Area Strategy. Journal of Behavioral and Experimental Finance, 19(4), 3638.

Long, W., Song, L., \& Tian, Y. (2018). A New Graphic Kernel Method of Stock Price Trend Prediction Based on Financial News Semantic and Structural Similarity. Expert Systems with Applications, Vol. 118, 411-424, https://doi.org/10.1016/j.eswa.2018.10.008

Mashayekh, Sh., Hadidi Fard, Sh., \& Pejman, S. (2013). The Impact of News References on Capital Market. Journal of Accounting Research, No. 8, 57-72.

Mehrara, M., Abdoli, G. (2006). The Asymmetry of Stock Market Volatility: The Case of Iran. Iranian Journal of Economic Research, 8(26), 25-40.

Moazeni, B., \& Asadollahi, F. (2013). Investigate Stock Price Manipulation and its Consequences. The First National Conference on Management and Accounting, Kharazmi International Educational and Research Institute.

Narayan, P. K. (2019). Can Stale Oil Price News Predict Stock Returns? Energy Economics, Vol. 83, 430-444. https://doi.org/10.1016/j.eneco.2019.07.022

Nelson, D. B. (1991). Conditional Heteroskedasticity in Asset Returns: A New Approach. Econometrica, 59(2), 347-370. https://doi.org/10.2307/2938260

Riahin, M., Madanchi, M. \& Setayesh, M. (2016). Evaluating Over-Response of Iranian Stock Market Investors to Nuclear Deals News. Journal of Economic, No. 16 (7), 53-77.

Seok, S. I., Cho, H., \& Ryu, D. (2019). Firm-Specific Investor Sentiment and the Stock Market Response to Earnings News. North American Journal of Economics and Finance, 48, 221-240. https://doi.org/10.1016/j.najef. 2019.01.014

Souri, A. (2020). Econometrics Using Eviews V.8 and STATA V.12, Volume I I. Cultural Studies Publications.

Wu, G. G., Hou, T. C., \& Lin, J. (2018). Can Economic News Predict Taiwan Stock Market Returns? Asia Pacific Management Review, Vol. 24 (1), 54-59. https://doi.org/10.1016/j.apmrv.2018.01.003 
Yahyazadeh far, M., Aghajani, H.A., \& Pakdin, A.R. (2010). Factors Affecting the Stock Price Index in Tehran Stock Exchange with Fuzzy Approach. Commercial Strategies Journal, Vol. 9 (47), 511-522.

Zhang, Y., Zhang, Z., Liu, L., \& Shen, D. (2017). The Interaction of Financial News between Mass Media and New Media: Evidence from News on Chinese Stock Market. Physica A: Statistical Mechanics and its Applications, Vol. 486, 535541.https://doi.org/10.1016/j.physa.2017.05.051

Zhao, R. (2019). Inferring Private Information from Online News and Searches: Correlation and Prediction in Chinese Stock Market. Physica A, 528(1800), 121450. https://doi.org/10.1016/j.physa.2019.121450 